\title{
Influence of optimization techniques and nano surface coating materials on microstructure of iron-nickel-chromium alloy using wire EDM process
}

\author{
R. Selvabharathi ${ }^{1, *}$, R. Ganapathy Srinivasan ${ }^{2}$, S. Palani ${ }^{2}$ \\ ${ }^{1}$ PSR Engineering College Sivakasi, India \\ ${ }^{2}$ Department of Mechanical Engineering, Vel Tech Multitech, Avadi, Chennai - 600062, Tamilnadu, India
}

\begin{abstract}
This research proposes developing the new hybrid optimization techniques for getting optimized wire EDM machining parameters and analysing the performance and microstructure of hybrid treatment alloy 20 material (high-velocity oxygen fuel spraying and plasma nitriding on iron-nickel-chromium alloy) after machining in wire EDM. The devising optimization is carried out using back-propagation neural networks (BPNN) integrated with fuzzy logic techniques. Taguchi L27 method uses optimized parameters in 3 factors and 3 level methods to BPNN wire EDM processing parameters. Those processing parameter errors are controlled by applying fuzzy logic system in hybrid optimization techniques. The hybrid optimization provides best results $( \pm 5 \%$ error) while comparing other techniques. This proposal was started with research review of defined factors and BPNN parameters level for hidden layer number, learning algorithm, neurons numbers, and so on. The analysis of variance (ANOVA), analysis of means (ANOM) and signal to noise $(\mathrm{S} / \mathrm{N})$ ratio have been used to identify Taguchi results. The BPNN techniques have been employed significantly to tackle hidden layer's uncertain parameter structures. The fuzzy logic controllers in general have been designed engaging the relations between system performance and factor through error method calculation. The microstructure analysis showed that the no evidence was found of recast layer formation on hybrid treated material after machining in wire EDM due to compressive stress and compound layer on material surface.
\end{abstract}

Keywords: measurement optimization; nano-coating; iron-nickel-chromium; microstructure; wire EDM

\section{Introduction}

Wire EDM is an unconventional machining process. The machine has been used for machining a heavy hardened material with complicated shape in best surface quality. It is used for cutting the material by means of electro-thermal energy to produced spark in every few microseconds. The spark is produced between the tool (wire electrode) and work piece. Here, the tool acts as moving through the stationary work piece. By this process, the tool almost enclosed by spark with the temperature around $12,000{ }^{\circ} \mathrm{C}$. In this environment, the great amount of heat is produced, and also the material has been removed by melting and evaporation [1]. Due to the high temperature environmental process, the tool and workpiece both are submerged in deionized water. The material surface and structure

*E-mail: krsbharathi@gmail.com has been changed due to the rapidly changing thermal environment during machining operation. That was affecting the surface characterizes, which consist of all the aspects of surface finish, surface metallurgy and surface topography. The machined surface consists of two criteria. First is the top surface of workpiece, which is covered surface texture. It is one of the reasons affecting surface roughness. Another one is surface metallurgy, which produces recast layer when machining the work piece [2]. At that time, the recast layer forms due to solidification by rapid cooling. This surface is called as white layer because it appears white in colour when observed in electron microscope images.

This layer was formed by thermal, chemical and mechanical effects on the material surface to remove material. It is also controlled by some phenomenon such as machining parameters (pulse on/off time, wire feed/speed, coolant pressure, etc.) and work piece [3, 4]. Literally, when 
the machining the surface was subjected to local thermal stress, the period of pulse on time, and the spark intensity with the coolant increases the temperature. From that, the current intensity and pulse on time affect the machined material surface roughness and hardness [5, 6]. Most of researchers are focusing on the optimized parameters with the surface integrity of material [7, 8]. Dhobe et al. [7] found that the heat treatment is also one of the affecting parameter. And Kondapalli Siva Prasad et al. [17] has been found that the effect of grain size in WEDM process. Similarly, R. K. Garg et. al [9] studied that the relation between heat treatment and white layer on material during wire EDM process. The hardness and heat treatment of work piece has been affecting the machinability [12]. The EDM achieved highest MRR, SR, TWR and dimensional accuracy when workpiece and tool (electrode) done by cryogenic treatment [11]. Similarly, when wire EDM was machining the work piece after plasma nitriding, there were no significant changes of formation of white layer on surface [10]. The hardening with double tempering gives better surface roughness compared to single tempering [13]. Mehmet Altug et. al [14] observed that the material treatment also affected the wire EDM machinability.

In recent years, most of the researchers have been developing various techniques to investigate the wire EDM performance on various materials using various modelling and new optimization techniques. The performance and surface characteristic of wire EDM has been investigated [15]. Artificial intelligence techniques, such as fuzzy logic and ANN, were successfully applied to various machining processes [16]. It has been examined and provided optimized result for material removal rate and surface roughness. The SA and F-ANN approach has been used to wire EDM process to correlate the input parameters with output performance. It was observed that the wire EDM performance can be improved by using new technique approach [17]. The wire EDM neural network modelling has been analysing formation of residual stress during machining in metal matrix composite. It has been noted that pulse off time has significant characteristics on

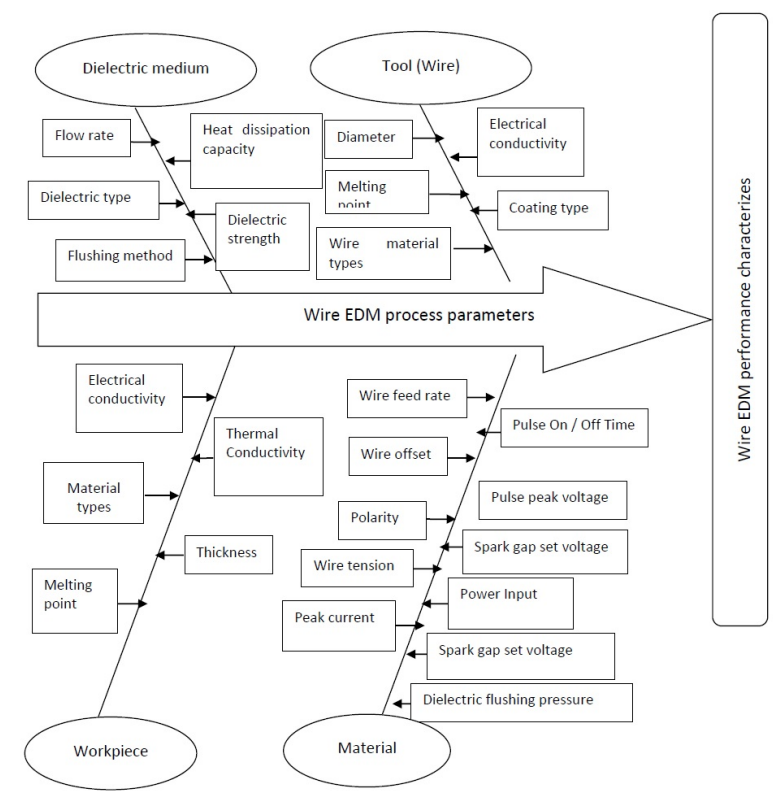

Fig. 1. Cause and effect diagram for performance characteristics in WEDM

the formation of residual stress [18]. The PCA integrated with Taguchi approach was recommended to investigate the pulse on/off time, particle size, wire tension volume fraction, wire wear rate, surface roughness and recast layer thickness during machining in wire EDM [19]. In this way, advanced modelling techniques like support vector machine, PSO, RSM, regression and analysis have been employed in research area [20-23]. In the literature survey based has been to investigate wire EDM performance and analysis material surface of iron-nickel-chromium alloy through the hybrid optimization techniques (Taguchi and ANFIS).

\section{Experimental details}

In the present study, alloy 20 material and $2 \mathrm{~mm}$ thickness plate were discussed. The chemical composition of alloy 20 material is shown in Table 1 . The alloy 20 material was applied HVOF molybdenum coating with the process temperature of $450{ }^{\circ} \mathrm{C}$ and then, plasma nitriding carried out maintaining the temperature of $500{ }^{\circ} \mathrm{C}$ in 12 hours [25]. Material specimen prepared as the dimensions of $150 \mathrm{~mm} \times 150 \mathrm{~mm} \times 2 \mathrm{~mm}$ was matched in material in the wire EDM. 


\subsection{Experimental producer using hybrid optimization techniques}

The experiment performance has been conducted on wire EDM as shown in Figure 1. It has brass wire with the diameter of $0.25 \mathrm{~mm}$ as cutting tool, deionized water consider to dielectric medium at constant atmospheric temperature. The flow chart diagram of the optimization techniques is shown in Figure 2. Three input variables as pulse on time $\left(\mathrm{T}_{\text {on }}\right)$, pulse off time $\left(\mathrm{T}_{\text {off }}\right)$ and wire feed (WT) has been used for machining on iron-nickelchromium alloy and measured output performance as surface roughness (SR) and material removal rate (MRR). The experimental work has been optimized L27 orthogonal array by Mintab software to get error less input and output as shown in Table 2. The Table 3 shows three levels of input parameters. The L27 orthogonal array has been conducted in $3 \times 3$ level. The below equation shows $\mathrm{S} / \mathrm{N}$ ratio (single to noise) input parameter.

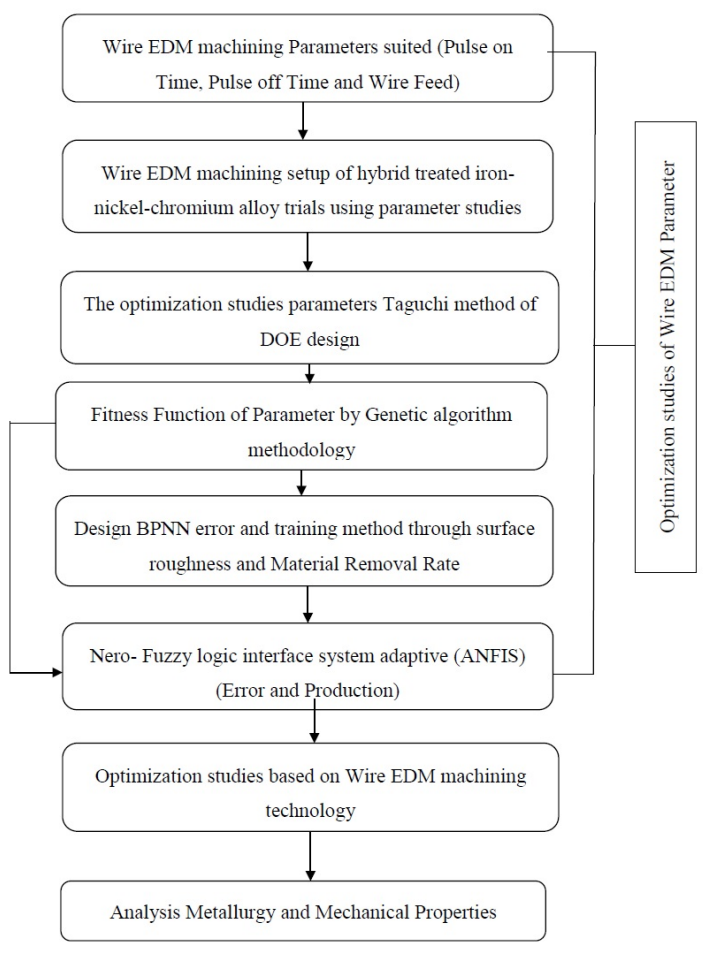

Fig. 2. Flow chart diagram of optimization techniques

The optimized output parameter founded in $\mathrm{S} / \mathrm{N}$ ratio has been employed to conduct the input variables. The surface roughness and material removal rate has been predicted by Taguchi method to get minimum error and more accuracy.

\subsection{Taguchi method}

Taguchi Method has been applied to experimental design through method employed orthogonal array to manage the process affecting parameters and their levels. It probably has to conduct all possible combination such as factorial design, Taguchi method combination test pair. These allow for collecting the data to find factors affecting the most output with least possible experimentations, which has been saving resource and time. ANOVA (analysis of variables) on the data collected to be used choosing new parameters for performance characterizes optimized. In order to find the study parameters, cause and effect diagram to determine potential parameters that affect machining characteristics (SR and MRR) was constructed. From the cause and effect diagram and literature review of wire EDM, we were choosing three input parameter for this investigation. In this investigation, $\mathrm{L}_{27}$ orthogonal array was with three control factors, that is, pulse on time, pulse off time and wire feed. Signal to noise ratio was obtained by using Minitab software. SR considered as lower is better (LB) and MRR considered as higher is better (HB) for determining optimized machining parameters. The loss function logarithmic transformation can be used to calculate $\mathrm{S} / \mathrm{N}$ ratio.

\subsection{Back propagation neural network}

Back propagation is a special type of neural network and it is also named as back propagation error method. It is mostly used for multi layered neural networks. In artificial neural network, one of the methods is back propagation neural network used to calculate gradient descent that is needed to calculate the weight of the network. This method uses a derivative of the squared error function with respect to the weights of the network. The back propagation neural network, otherwise backward propagation error method, mainly look for error function, even then having the minimum value of weight space is known as rule or gradient descent. The 
Table 1. Chemical composition of alloy 20 (in wt\%)

\begin{tabular}{lllllllllll}
\hline Si & S & P & Mn & C & Nb & Mo & Cu & Cr & Fe & Ni \\
\hline \hline 1 & 0.035 & 0.045 & 2 & 0.07 & 1 & 3 & 4 & 21 & 29.85 & 38 \\
\hline
\end{tabular}

Table 2. Process parameters employed for EDM

\begin{tabular}{cccccc}
\hline Parameter & \multirow{2}{*}{ Unit } & Factor & \multicolumn{3}{c}{ Level } \\
\cline { 4 - 6 } & & & $\mathbf{1}$ & $\mathbf{2}$ & $\mathbf{3}$ \\
\hline \hline Pulse on time & $(\mu$ sec $)$ & $\mathbf{A}$ & 106 & 116 & 126 \\
Pulse off time & $(\mu$ sec $)$ & $\mathrm{B}$ & 40 & 50 & 60 \\
Wire feed & $(\mathbf{m} / \mathbf{m i n})$ & $\mathrm{C}$ & 4 & 8 & 12 \\
\hline
\end{tabular}

Table 3. EDM process parameter of Taguchi L27 orthogonal array

\begin{tabular}{|c|c|c|c|}
\hline \multirow{2}{*}{ Experimental trials } & \multicolumn{3}{|c|}{ Factor } \\
\hline & $\mathbf{A}$ & B & $\mathbf{C}$ \\
\hline 1 & 1 & 1 & 1 \\
\hline 2 & 1 & 1 & 2 \\
\hline 3 & 1 & 1 & 3 \\
\hline 4 & 1 & 2 & 1 \\
\hline 5 & 1 & 2 & 2 \\
\hline 6 & 1 & 2 & 3 \\
\hline 7 & 1 & 3 & 1 \\
\hline 8 & 1 & 3 & 2 \\
\hline 9 & 1 & 3 & 3 \\
\hline 10 & 2 & 1 & 1 \\
\hline 11 & 2 & 1 & 2 \\
\hline 12 & 2 & 1 & 3 \\
\hline 13 & 2 & 2 & 1 \\
\hline 14 & 2 & 2 & 2 \\
\hline 15 & 2 & 2 & 3 \\
\hline 16 & 2 & 3 & 1 \\
\hline 17 & 2 & 3 & 2 \\
\hline 18 & 2 & 3 & 3 \\
\hline 19 & 3 & 1 & 1 \\
\hline 20 & 3 & 1 & 2 \\
\hline 21 & 3 & 1 & 3 \\
\hline 22 & 3 & 2 & 1 \\
\hline 23 & 3 & 2 & 2 \\
\hline 24 & 3 & 2 & 3 \\
\hline 25 & 3 & 3 & 1 \\
\hline 26 & 3 & 3 & 2 \\
\hline 27 & 3 & 3 & 3 \\
\hline
\end{tabular}

weights that can minimize the error function are then considered to be a solution.

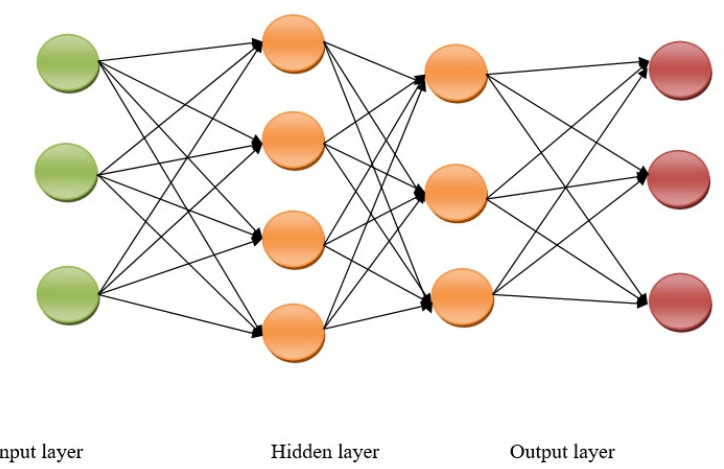

Fig. 3. BPNN model used for process parameter analysis and optimization techniques

BPNN is a feed forward neural network. Backpropagation, an abbreviation for "backward propagation of errors" is a common method of training ANN. In 1986, Rumelhart et al. had described a new supervised learning procedure known as back propagation neural network (BPNN), which is used for linear as well as non-linear classification. From a desired output, the network learns from many inputs. In BPNN, the errors are back propagated to the input layer. BPNN is a supervised algorithm in which error difference between the desired output and calculated output is back propagated. The procedure is repeated during learning to minimize the error by adjusting the weights through the back propagation of error. As a result of weight adjustments, hidden units set their weights to represent 
Table 4. Cumulative experimental data of EDM process.

\begin{tabular}{|c|c|c|c|c|c|}
\hline SI.NO & $\begin{array}{l}\text { Pulse on time } \\
\text { T ON }(\mu \text { sec }) \\
\end{array}$ & $\begin{array}{l}\text { Pulse off time } \\
\text { T OFF }(\mu \text { sec }) \\
\end{array}$ & $\begin{array}{c}\text { Wire feed } \\
\text { WF (m/min) }\end{array}$ & $\begin{array}{c}\text { Material removal rate } \\
\text { MRR }(\mathbf{m m} / \mathbf{m i n})\end{array}$ & $\begin{array}{c}\text { Surface roughness } \\
\text { SR }(\mu \mathrm{m})\end{array}$ \\
\hline 1 & 106 & 40 & 4 & 0.68 & 1.385 \\
\hline 2 & 106 & 40 & 8 & 0.71 & 1.255 \\
\hline 3 & 106 & 40 & 12 & 0.505 & 1.175 \\
\hline 4 & 106 & 50 & 8 & 0.48 & 1.35 \\
\hline 5 & 106 & 50 & 12 & 0.405 & 1.265 \\
\hline 6 & 106 & 50 & 4 & 0.2 & 1.105 \\
\hline 7 & 106 & 60 & 12 & 0.315 & 1.35 \\
\hline 8 & 106 & 60 & 4 & 0.165 & 1.14 \\
\hline 9 & 106 & 60 & 8 & 0.165 & 1.08 \\
\hline 10 & 116 & 40 & 12 & 2.405 & 2.57 \\
\hline 11 & 116 & 40 & 4 & 2.205 & 2.39 \\
\hline 12 & 116 & 40 & 8 & 0.75 & 1.435 \\
\hline 13 & 116 & 50 & 4 & 1.54 & 2.525 \\
\hline 14 & 116 & 50 & 8 & 0.58 & 1.38 \\
\hline 15 & 116 & 50 & 12 & 0.66 & 1.72 \\
\hline 16 & 116 & 60 & 8 & 0.47 & 1.63 \\
\hline 17 & 116 & 60 & 12 & 0.625 & 1.85 \\
\hline 18 & 116 & 60 & 4 & 0.5 & 1.625 \\
\hline 19 & 126 & 40 & 8 & 3.4 & 2.9 \\
\hline 20 & 126 & 40 & 12 & 1.26 & 1.85 \\
\hline 21 & 126 & 40 & 4 & 2.2 & 2.66 \\
\hline 22 & 126 & 50 & 12 & 0.91 & 2.08 \\
\hline 23 & 126 & 50 & 4 & 1.66 & 2.635 \\
\hline 24 & 126 & 50 & 8 & 1.54 & 2.445 \\
\hline 25 & 126 & 60 & 4 & 1.34 & 2.855 \\
\hline 26 & 126 & 60 & 8 & 1.345 & 2.56 \\
\hline 27 & 126 & 60 & 12 & 0.29 & 1.295 \\
\hline
\end{tabular}

important features of the task domain. It has the capability to establish the connection between HVS parameter values and FIS output values by adjusting the neural network weights and bias before and after embedding watermark. Owning to use of neural network, watermark can be extracted without the host signal, and therefore, reduce the boundary in practical applications.

BPNN consists of three layers: 1) input layer, 2) hidden layer, and 3) output layer. The number of hidden layers, and the number of hidden units in each hidden layer depends upon the complexity of the problem as shown in Figure 3.

During this step, error is calculated by difference between the targeted output and actual output of each output unit. This error is back propagated to the previous layer, that is, hidden layer. For each unit in the hidden layer N, error at that node is calculated. In a similar way, error at each node of previous hidden layer, that is, $\mathrm{N}-1$ is calculated. These calculated errors are used to correct the weights so that the error at each output unit is minimized. Forward and backward steps are repeated 
until the error is minimized up to the expected level. The training algorithm of back propagation includes four stages: 1. initialization of weights, 2 . feed forward, 3. back propagation of errors, 4. updating the weights and biases. The bias acts like weights on the connection from units whose output is always 1. During initialization of weights, some arbitrary values are given initially to give some output by feed forwarding through the layers. So, the difference between the obtained and actual values is calculated as error and back propagated. High initial weight will result in 90 a faster learning rate. But weights may oscillate. If initial weights are too small, then learning rate will be slow (Table 5). For best results, initial weights may be considered between -0.5 to 0.5 or -1 to 1 . In back propagation method first, the output of hidden layer is calculated by the formula:

$$
H_{i}=f\left(\sum w_{i j} X_{i}-a_{j}\right) j=1,2 \ldots, l
$$

where and $f$ represent the output of hidden layer and the incentive function of neurons, 1 is the neuron number of hidden layer, $\mathrm{n}$ is the neuron number of the input layer, is the weight factor between input-layer and hidden layer, is threshold value. The next step is to predict the output values by using the formula:

$$
o_{k}=\sum H_{i} w_{i k}-b_{k} k=1,2, \ldots, m
$$

where is threshold value, $\mathrm{m}$ is the neuron number of the output layer. Then, according to the prediction error calculated by the difference between the predicted output and the expected output, weight factor and threshold value can be updated as follows:

$$
\begin{gathered}
\omega_{i j}=\omega_{i j}+\eta H_{i}\left(1-H_{i}\right) X(i) \sum \omega_{i k} e_{i k} \\
i=1,2, \ldots, n: j=1,2, \ldots, l \\
\omega_{i j}=\omega_{i k}+\eta H_{i} e_{k} j=1,2, \ldots, m \\
a_{1}=a_{j}+\eta H_{i}\left(1-H_{i}\right) x(i) \sum \omega_{i k} e_{k} j=1,2, \ldots, l \\
b_{k}=b_{k}+e_{k} k=1,2, \ldots, m
\end{gathered}
$$

One of the more popular activation functions for backpropagation networks is the sigmoid, a real function sc: IR $\rightarrow(0,1)$ defined by the expression. The constant $\mathrm{c}$ can be selected arbitrarily and its reciprocal $1 / \mathrm{c}$ is called the temperature parameter in stochastic neural networks. An alternative to the sigmoid is the symmetrical sigmoid $\mathrm{S}(\mathrm{x})$.

Generally, there are two types of learning methods as follows: 1. sequential learning or pre-pattern method, 2. batch learning or pre-epoch method. In sequential learning, a given input pattern is broadcasted forward and then the error is calculated and back propagated, the weights are reorganized until we get the targeted output. In batch learning, the weights are reorganized only after the entire set of training network has been offered to the network. Thus, the weights are updated after every epoch.

\subsection{Adaptive neuro-fuzzy interference system (ANFIS)}

Due to changes in network environment, in a dynamic environment in need of an optimization algorithms, which learn from the experimental results and find the optimum solution to the end user. So many soft computing techniques are evolved such as artificial neural network, fuzzy logic system, and genetic algorithms, as shown in Figure 4.

To minimize output errors in fuzzy modelling system, it needs trial steps and auxiliary calculation for adjusting the fuzzy membership functions. Because there are no proper methods to convert the human idea into the knowledge part of the fuzzy system, which leads the system output inadaptability nature. In the case of artificial neural network, it having good adaptability of output based on the input parameters and it also support the non-linear correlation between the input and output parameters. To improve the performance combining the advantages of both FIS and ANN, it is called as ANFIS. This ANFIS supports the knowledge and adaption features.

Jang combines the advantages of fuzzy interference system (FIS) with artificial neural network (ANN) and named as adaptive neuro fuzzy interference system (ANFIS), which consists of multi-layer approaches. ANFIS consists of 
Table 5. BPNN parameters and interlayer details

\begin{tabular}{|c|c|c|c|c|}
\hline Name & Number & No. & MRR & SR \\
\hline parameter. Show & 50 & \multirow{2}{*}{$1^{\text {st }}$} & \multirow{2}{*}{9} & \multirow{2}{*}{9} \\
\hline Maximum parameter. Epochs & 1000 & & & \\
\hline Number of input parameter & 3 & \multirow[t]{2}{*}{$2^{\text {nd }}$} & \multirow[t]{2}{*}{8} & \multirow[t]{2}{*}{10} \\
\hline Number of output parameter & 1 & & & \\
\hline
\end{tabular}

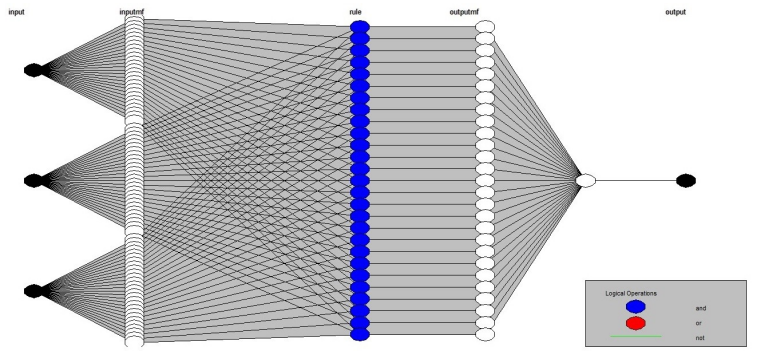

Fig. 4. Adaptive neuro-fuzzy interference system (ANFIS)

fuzzification, rule, normalization, defuzzification and output layers, as shown in the figure.

Jang developed network system (ANFIS) as a rule based system and it learns/decides the rules from the training data. Two different types of methods are used in FIS such as Mamdani and TakagiSugeon-Kang (TSK). In our system, we use the TSK approach to derive the optimized results. Here rules are mainly focusing on the input output relationship such as if this is the input parameter then what will be the output; simply if-then rules are used for correlating the input and output values.

IF $a$ is $X_{1}$ and $b$ is $Y_{1}$ THEN $f_{1}=p_{1} a+q_{1} b+r_{1}$

IF $a$ is $X_{2}$ and $b$ is Y2 THEN $f_{2}=p_{2} a+q_{2} b+r_{2}$

IF $a$ is $X_{n}$ and $b$ is $Y_{n}$ THEN $f_{1}=p_{n} a+q_{n} b+r_{n}$

The values of $p, q$ and $r$ constant that can be evaluated during the training process based on the training data. Next step is to form fuzzy rules by combining these functions by the ANFIS. In this layer, it receives input from the external source and it assigns the member function to all the input values based on the weights. This is an adaptive layer so based on the input fuzzy set assign a member function to each input values:

$$
O_{1}^{1}=\mu_{X i}(a) \text { fori }=1,2, \ldots n
$$

Layer 2 - rule layer

In this model, there are two type of rules can be applied by the system such as AND and OR rule. Our proposed work adopts the AND rule to provide the relative strength information about input values, considered as firepower of all the fuzzy rules. Product of all the input membership value is considered as output of this layer.

$$
O_{i}^{2}=w_{i}=\mu_{X i}(a) * \mu y_{i}(a)
$$

Layer 3 - normalization layer

Third layer is a Normalized layer. This is to normalize all the firing strength based on each rule's weight to all the rules' weights.

It can be calculated as:

$$
O_{i}^{3}=w i
$$

Layer 4 - defuzzification

Defuzzification is an adaptive layer, which uses the first order function to form $\mathrm{f}_{\mathrm{i}}=\mathrm{p}_{\mathrm{i}} \mathrm{x}+\mathrm{q}_{\mathrm{i}} \mathrm{y}+\mathrm{k}_{\mathrm{i}}$. The derived output this layer is in the form of:

$$
O_{i}^{4}=w_{i} f_{i}=w_{i}\left(p_{i} x+q_{i} y+k_{i} .\right.
$$

Layer 5 - output layer

This is an output layer. From this layer, we get the final output of this network by sum of all the input layers by using the formula:

$$
O_{i}^{5}=f i=\Sigma w_{i} f_{i}=\Sigma\left[w_{i}\left(p_{i} x+q_{i} y+k_{i}\right] .\right.
$$

Finally, by having ANFIS, the input values are mapped with output values to get the optimized 
results. This method follows the values that are grouped into two set such as training data and checking data. In ANFIS, a combination of the back propagation and least square methods are used to train the input values. The result of the training data is prediction of error in a minimized manner.

\section{Results and discussion}

\subsection{Hybrid optimization of process pa- rameter studies}

The Taguchi model was used for the optimization of signal response. The performance output, surface roughness (SR) was the type "lower the better" and material removal rate was the type "higher the better". The S/N ratio was examined by loss function logarithmic transformation, which was given by Xiong [29] as shown in the following equation:

$$
\frac{S}{N} \text { ratio }=\mid-10 \log _{10}\left[\frac{1}{n} \sum_{i=1}^{n} y_{i}^{2}\right]
$$

The ANOVA model was conducted using the MINITAB-19 software in order to examine the significant input parameters. The three types of parameters were the deciding factor of WDM: pulse on time, pulse off time, wire feed as shown in Figure 5(a) \& 5(b). Higher F value and lower $\mathrm{P}$ value mention the importance degree of every input parameter on material removal rate and surface roughness of hybrid treated iron-nickel-chromium alloy at $95 \%$ confidence level as shown in Table 6 and 7.

The BPNN gives better performance. Hence, we were required to develop confidence level and overall best fit model performance, as shown in Figure 6. For that, we had to input parameter in ANFIS. The figure shows the ANFIS model simulation results in the form of graphical rules. It is noted that the performance output probability was maximum by varying input parameters and also by applying the if-then rules:

If (pulse on time is low) and (wire feed is low) and (signal to noise ratio is high), then (surface roughness is high).

If (pulse on time is moderate) and (wire feed is

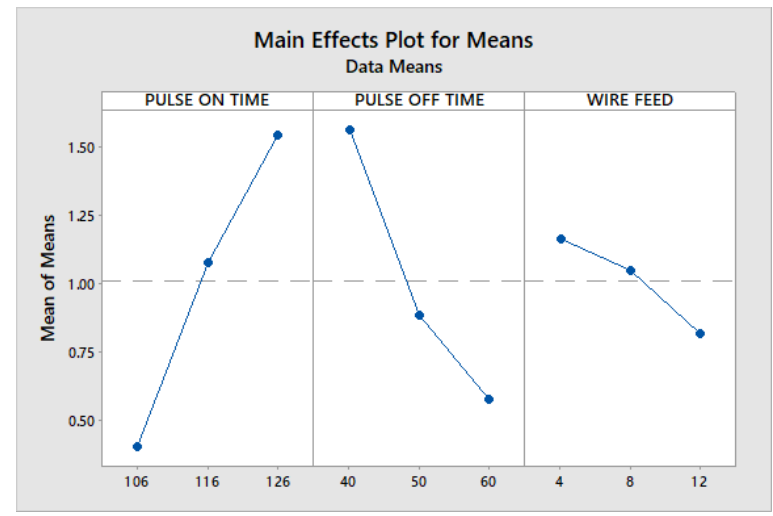

(a)

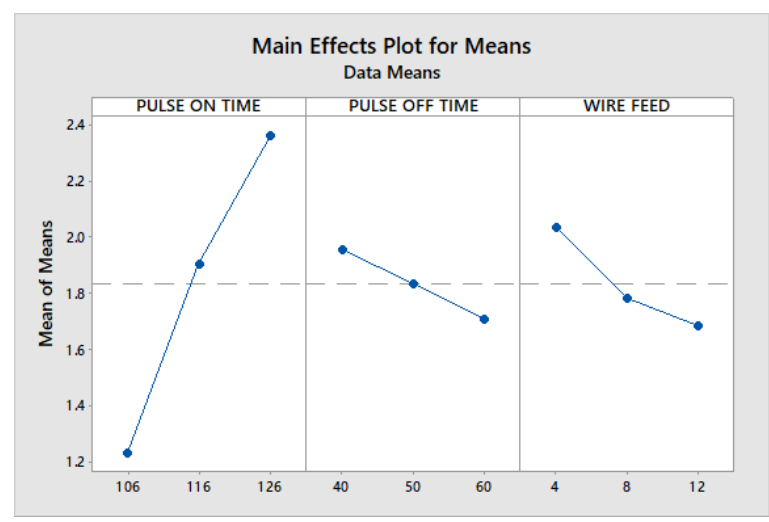

(b)

Fig. 5. (a) Plot diagram of material removal rate; (b) Plot diagram of surface roughness SR $(\mu \mathrm{m})$

moderate) and (signal to noise ratio is high), then (surface roughness is high).

If (pulse on time is moderate) and (wire feed is low) and (signal to noise ratio is high), then (surface roughness is high).

If (pulse on time is moderate) and (wire feed is low) and (signal to noise ratio is moderate) then (surface roughness is high).

If (pulse on time is high) and (wire feed is moderate) and (signal to noise ratio is high), then (surface roughness is high).

If (pulse on time is high) and (wire feed is low) and (signal to noise ratio is high), then (surface roughness is high).

The Figure 7 shows that the correlation of the input parameters to output performance of wire EDM. From this, we can clearly concluded that the output performance as material removal rate 
Table 6. Regression ratio of material removal rate

\begin{tabular}{lccccc}
\hline Source & DF & Adj SS & Adj MS & F-Value & P-Value \\
\hline \hline Regression & 3 & 13.1260 & 4.3753 & 21.32 & 0.000 \\
$\begin{array}{l}\text { Pulse on time } \\
\text { t on }(\mu \text { sec) }\end{array}$ & 1 & 7.8095 & 7.8095 & 38.06 & 0.450 \\
Pulse off time & 1 & 5.0545 & 5.0545 & 24.63 & 0.300 \\
t on $(\mu$ sec) & 1 & 0.2620 & 0.2620 & 1.28 & 0.250 \\
Wire feed & 23 & 4.7195 & 0.2052 & & \\
Error & 26 & 17.8454 & & & \\
Total & & & & & \\
\hline
\end{tabular}

Table 7. Regression ratio of surface roughness SR $(\mu \mathrm{m})$

\begin{tabular}{lccccc}
\hline Source & DF & Adj SS & Adj MS & F-Value & P-Value \\
\hline \hline Regression & 3 & 1.96406 & 0.65469 & 16.14 & 0.000 \\
Pulse on time & 1 & 1.76964 & 1.76964 & 43.62 & 0.420 \\
t on $(\mu$ sec) & 1 & 0.08050 & 0.08050 & 1.98 & 0.470 \\
Pulse off time & 1 & 0.11392 & 0.11392 & 2.81 & 0.210 \\
$t$ on $(\mu$ sec) & 23 & 0.93314 & 0.04057 & & \\
Wire feed & 26 & 2.89719 & & & \\
Error & & & & & \\
Total & & &
\end{tabular}
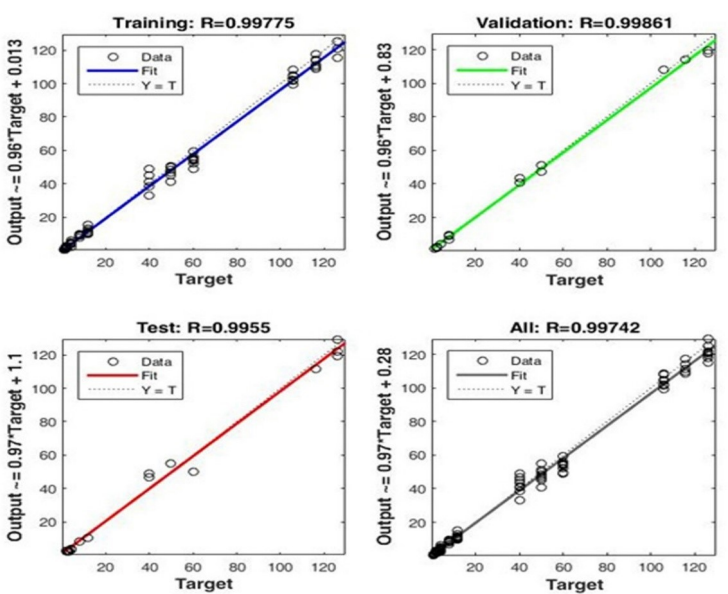

Fig. 6. The best fitness value estimated by BPNN model of (a) Material removal rate (b) Surface roughness SR $(\mu \mathrm{m})$

was high when the pulse on time and wire feed became maximum and also surface roughness was high while the pulse on time and wire feed became minimum. Similarly, the pulse off time was minimum the performance output as material removal rate became high and surface roughness was less. The BPNN error calculation methods were implemented at the output parameters such as experimentation output parameters value (EOP) and prediction of back propagation neural network output parameters (BPOP), as shown in Table 8 (a) and 8 (b).

The graph shows the details of the predicted value obtained by Taguchi, back propagation neural network, fuzzy logic system modelling and hybrid ANFIS model. To investigate the scattering about the agreement line (45 degrees line), one line was plotted in the range within the $2 \%$ error and then two more lines, which was Taguchi, BPNN and fuzzy logic, were over, then the range of $4,6,12 \%$ error was conceived. It was calculated that the predicted value accommodated by Taguchi, BPNN model and fuzzy model generated over the range $99 \%$ of accuracy, which obtained the reliability of models as shown in Table 9. The hybrid ANFIS model dominated the Taguchi, BPNN model and fuzzy logic model, and the reason of the maximum of hybrid ANFIS model predicted values were plotted on the agreement line. 
Table 8. (a) $1^{\text {st }}$ EDM Process parameter of alloy 20 materials; (b) $2^{\text {nd }}$ EDM Process parameter of alloy 20 materials

\begin{tabular}{crrrrrr}
\hline \multirow{2}{*}{ No } & \multicolumn{3}{c}{$\begin{array}{c}\text { MRR } \\
(\mathbf{m m} / \mathbf{m i n})\end{array}$} & \multicolumn{3}{c}{ SR $(\mu \mathbf{m})$} \\
\cline { 2 - 7 } & EOP & BPOP & ERROR & \multicolumn{1}{c}{ EOP } & BPOP & ERROR \\
\hline \hline 1 & 0.68 & 0.5643 & 11.57 & 1.385 & 1.3627 & 2.23 \\
2 & 0.71 & 0.7451 & -3.51 & 1.255 & 1.2712 & -1.62 \\
4 & 0.48 & 0.4921 & -1.21 & 1.35 & 1.3215 & 2.85 \\
10 & 2.405 & 2.4184 & -1.34 & 2.57 & 2.3954 & 17.46 \\
14 & 0.58 & 0.5683 & 1.17 & 1.38 & 1.4725 & -9.25 \\
17 & 0.625 & 1.0514 & -42.64 & 1.85 & 2.3891 & -53.91 \\
22 & 0.91 & 0.9244 & -1.44 & 2.08 & 2.0176 & 6.24 \\
23 & 1.66 & 1.7587 & -9.87 & 2.635 & 2.7871 & -15.21 \\
25 & 1.34 & 1.3572 & -1.72 & 2.855 & 2.8142 & 4.08 \\
\hline
\end{tabular}

\begin{tabular}{crrrrrr}
\hline \multirow{2}{*}{ No } & \multicolumn{3}{c}{$\begin{array}{c}\text { MRR } \\
(\mathbf{m m} / \mathbf{m i n})\end{array}$} & \multicolumn{3}{c}{ SR $(\mu \mathrm{m})$} \\
\cline { 2 - 7 } & EOP & BPOP & ERROR & EOP & BPOP & ERROR \\
\hline \hline 3 & 0.505 & 0.6383 & -13.33 & 1.175 & 1.1254 & 4.96 \\
6 & 0.2 & 0.1662 & 3.38 & 1.105 & 1.1031 & 0.19 \\
9 & 0.165 & 0.1675 & -0.25 & 1.08 & 1.1182 & -3.82 \\
12 & 0.75 & 0.7593 & -0.93 & 1.435 & 1.4258 & 0.92 \\
15 & 0.66 & 0.6247 & 3.53 & 1.72 & 1.7467 & -2.67 \\
18 & 0.5 & 0.7124 & -21.24 & 1.625 & 1.6024 & 2.26 \\
20 & 1.26 & 1.4972 & -23.72 & 1.85 & 1.4358 & 41.42 \\
24 & 1.54 & 1.5524 & -1.24 & 2.445 & 2.5123 & -6.73 \\
26 & 1.345 & 1.3571 & -1.21 & 2.56 & 2.5917 & -3.17 \\
\hline
\end{tabular}

Table 9. Results of BPNN-ANFIS optimization

\begin{tabular}{|c|c|c|c|c|c|}
\hline \multirow{2}{*}{ Sl. No. } & \multicolumn{3}{|c|}{ Input parameters } & \multicolumn{2}{|c|}{ Output parameters } \\
\hline & $\begin{array}{c}\text { Pulse on } \\
\text { time } \\
(\mu \text { sec }) \\
\end{array}$ & $\begin{array}{l}\text { Pulse off time } \\
\quad(\mu \text { sec })\end{array}$ & $\begin{array}{c}\text { Wire feed } \\
(\mathrm{m} / \mathrm{min})\end{array}$ & $\begin{array}{c}\text { Optimal } \\
\text { value }(\mathbf{m m})\end{array}$ & $\begin{array}{c}\text { Machining } \\
\text { performance }\end{array}$ \\
\hline 1. & 110 & 80 & 10 & 0.184 & Material removal rate \\
\hline 2. & 106 & 60 & 10 & 1.95 & Surface roughness \\
\hline
\end{tabular}

While in case of Taguchi, BPNN and fuzzy modelling, some more predicted values were crossing the $2 \%$ of error, as shown in Figure 8. Consequently, the Taguchi, BPNN and fuzzy models were dominated by the hybrid ANFIS model. The Taguchi gives the largest mean error predicted value, which was $4.56 \%$ followed by fuzzy logic within the mean error $2.78 \%$; BPNN model gave
$1.52 \%$ mean error and hybrid ANFIS employed mean error of $0.5 \%$. ANFIS Taguchi hybrid algorithm is made to be optimized and develop advantages, while it can solve nonlinear functions and approximation problems. In addition, the hybrid algorithm is a flexible and robust tool that can engage predictive and confidence interval prediction $99.79 \%$ in hybrid ANFIS model. It is very close to 

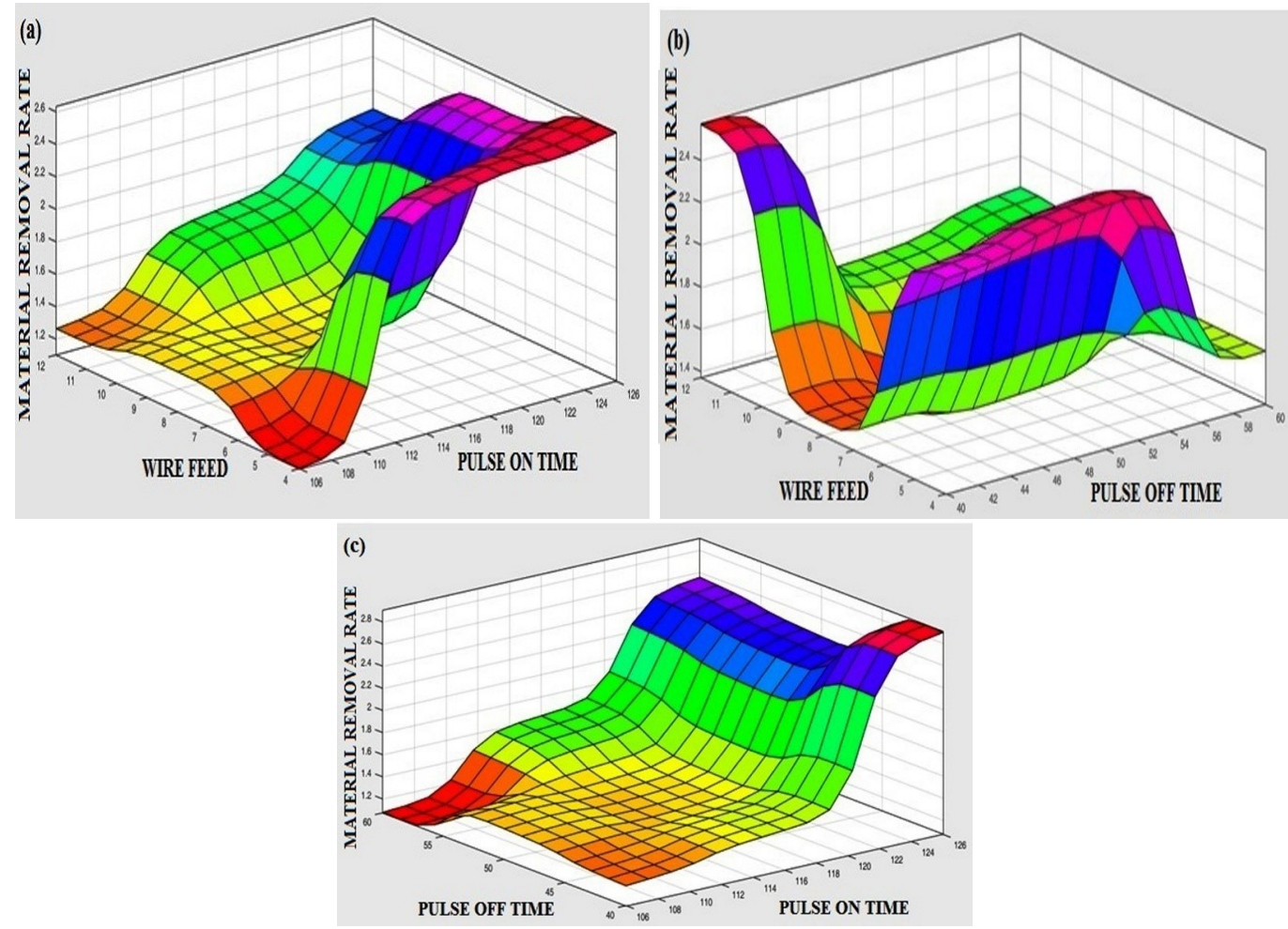

Fig. 7. Plot diagram of material removal rate of ANFIS model
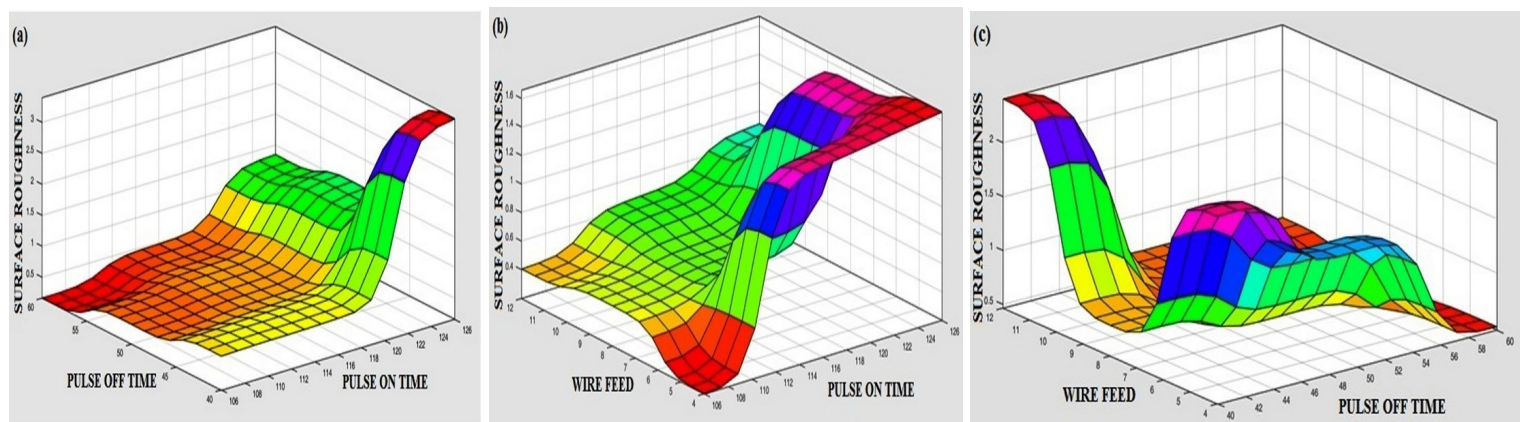

Fig. 8. Plot diagram of surface roughness of ANFIS model

the actual value (Table 10).

\subsection{Metallurgical and mechanical proper- ties}

The analysis of metallurgical and mechanical properties of iron-nickel-chromium alloy and hybrid treated iron-nickel-chromium alloy was carried out after machining in wire EDM. Ganapathy Srinivasan et.al [24] investigated the hybrid treated iron-nickel-chromium alloy before machin- ing; it had deposition compound layer form as presence of $\mathrm{Mo}_{\mathrm{X}} \mathrm{N}, \mathrm{Fe}_{\mathrm{X}} \mathrm{N}, \mathrm{CrN}, \mathrm{Ni}_{\mathrm{X}} \mathrm{N}$, and thin $\mathrm{FCC}$ $\mathrm{M}$ phase. That layer produced compressive residual stress on the material surface. The Figure 9 (a) and (b) shows the SEM analysis of iron-nickelchromium alloy before and after machining in wire EDM. Figure 9(a) clearly shows the formation of recast layer on the surface of the material. The recast layer was formed as shrinkage of melted material and rapid solidification that induced tensile residual and high thermal stress, which produced 

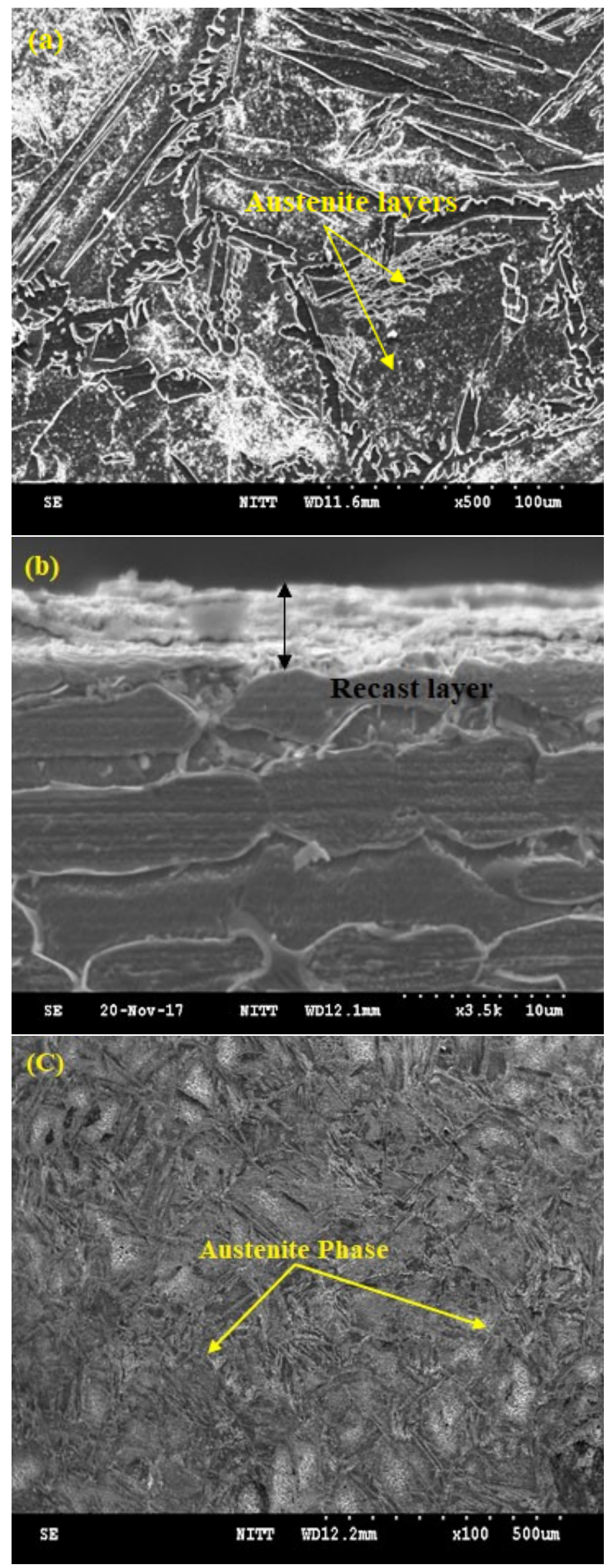

Fig. 9. SEM analysis a) Alloy 20 materials b) Coating materials c) Hybrid treated alloy 20 microstructure after machining micro cracks on surface [25]. Y.S Tarng et. al [26] observed that the recast layer lead to changes of microstructure as an austenite $(\sqrt{ } /-\mathrm{Fe})$. This phase was not observed in the material before machining. The tensile residual stress of recast layer increased the effect of maximum shear stress, which lead to indentation depth and plastic deformation [27]. These affect the mechanical properties of material after machining. Figure 9 (c) shows that the SEM analysis of hybrid treated iron-nickel-chromium alloy after machining in wire EDM same machining parameters. It clearly shows that no evidence was found regarding the formation of recast layer on the surface after machining. This effect is believed to be due to the fact that the tensile and thermal stress effect was balanced by the presence of compressive residual stress in hybrid treated material [28]. And also the crack propagation and micro holes were not noted in the machined surface. Due to this reason, there were no significant changes in the mechanical properties.

\section{Conclusion}

By the experimental investigation and optimization of wire EDM process parameters for hybrid coating on iron-nickel-chromium, we conclude:

- The hybrid optimization techniques gives better optimized result when compared to Taguchi, BPNN and fuzzy logic.

- The error was calculated. The BPNN method was used in material removal rate and surface roughness. BPNN appears to acquiesce an error percentage of 4,8 and 12 , respectively, indicating its high degree of consistency.

- In the confirmation test, the errors of -16.29 and $12.58 \%$ were noticed between the experiment result and the predicted result by BPNN-GA model for material removal rate and surface roughness, respectively.

- The hybrid surface treated specimen after wire EDM machining observed that the formation of recast layer on machining surface 
Table 10. EDM process parameters and error of confirmation experiment

\begin{tabular}{cccccc}
\hline & \multicolumn{3}{c}{ Input parameters } & \multicolumn{2}{c}{ Output parameters } \\
& $\begin{array}{c}\text { Pulse on } \\
\text { time } \\
(\mu \text { sec })\end{array}$ & $\begin{array}{c}\text { Pulse off time } \\
(\mu \text { sec })\end{array}$ & $\begin{array}{c}\text { Wire feed } \\
(\mathbf{m} / \mathbf{m i n})\end{array}$ & $\begin{array}{c}\text { Material removal } \\
\text { rate } \\
(\mathbf{m m} / \mathbf{m i n})\end{array}$ & $\begin{array}{c}\text { Surface } \\
\text { roughness } \\
(\mu \mathbf{m})\end{array}$ \\
\hline \hline $\begin{array}{c}\text { Experiment } \\
\text { predicted by } \\
\text { BPNN-ANFIS } \\
\text { model }\end{array}$ & 106 & 60 & 8 & 0.155 & 1.08 \\
Error \% & 105.7 & 59 & 8 & 0.1675 & 1.1182 \\
\hline
\end{tabular}

was minimum as compared to the without treated material.

- Formation of pore and cracks were less in the hybrid treated machining specimen due to the presence of twin boundaries and grain boundary thickness.

\section{References}

[1] Ablyaz, T.R. and Belinin, D.S., 2014. Wire electrical discharge machining of items after plasmatic surface hardening. Middle-East Journal of Scientific Research, 19(8), pp.1096-1098.

[2] Altug, M., Erdem, M. and Ozay, C., 2015. Experimental investigation of kerf of Ti6Al4V exposed to different heat treatment processes in WEDM and optimization of parameters using genetic algorithm. The International Journal of Advanced Manufacturing Technology, 78(912), pp.1573-1583.

[3] Azam, M., Jahanzaib, M., Abbasi, J.A., Abbas, M., Wasim, A. and Hussain, S., 2016. Parametric analysis of recast layer formation in wire-cut EDM of HSLA steel. The International Journal of Advanced Manufacturing Technology, 87(1-4), pp.713-722.

[4] Bosheh, S.S. and Mativenga, P.T., 2006. White layer formation in hard turning of $\mathrm{H} 13$ tool steel at high cutting speeds using CBN tooling. International Journal of Machine Tools and Manufacture, 46(2), pp.225-233.

[5] Çaydaş, U., Hasçalık, A. and Ekici, S., 2009. An adaptive neuro-fuzzy inference system (ANFIS) model for wire-EDM. Expert Systems with Applications, 36(3), pp.6135-6139.

[6] Choi, K.K., Nam, W.J. and Lee, Y.S., 2008. Effects of heat treatment on the surface of a die steel STD11 machined by W-EDM. Journal of materials processing technology, 201(1-3), pp.580-584.

[7] Dhobe, M.M., Chopde, I.K. and Gogte, C.L., 2013. Effect of heat treatment and process parameters on surface roughness in wire electro discharge machining. Int. J. Mech. Eng. \& Rob. Res, 2(2), pp.275-281.

[8] Dhobe, M.M., Chopde, I.K. and Gogte, C.L., 2013. Investigations on surface characteristics of heat treated tool steel after wire electro-discharge machining. $\mathrm{Ma}$ terials and manufacturing processes, 28(10), pp.11431146.
[9] Garg, R.K., Singh, K.K., Sachdeva, A., Sharma, V.S., Ojha, K. and Singh, S., 2010. Review of research work in sinking EDM and WEDM on metal matrix composite materials. The International Journal of Advanced Manufacturing Technology, 50(5-8), pp.611-624.

[10] Kapoor, J., Khamba, J.S. and Singh, S., 2012. The effect of machining parameters on surface roughness and material removal rate with cryogenic treated wire in WEDM. International Journal of Machining and Machinability of Materials 2, 12(1-2), pp.126-141.

[11] Khan, A.A., Ali, M.B.M. and Shaffiar, N.B.M., 2006. Relationship of surface roughness with current and voltage during wire EDM. Journal of applied sciences, 6(10), pp.2317-2320.

[12] Manevski, K., Børgesen, C.D., Li, X., Andersen, M.N., Abrahamsen, P., Hu, C. and Hansen, S., 2016. Integrated modelling of crop production and nitrate leaching with the Daisy model. MethodsX, 3, pp.350-363.

[13] Marafona, J.D. and Araujo, A., 2009. Influence of workpiece hardness on EDM performance. International Journal of Machine Tools and Manufacture, 49(9), pp.744-748.

[14] Morotti, S. and Grandi, E., 2017. Logistic regression analysis of populations of electrophysiological models to assess proarrythmic risk.Methods $X, 4$, pp.25-34.

[15] Nain, S.S., Garg, D. and Kumar, S., 2018. Investigation for obtaining the optimal solution for improving the performance of WEDM of super alloy Udimet-L605 using particle swarm optimization. Engineering science and technology, an international journal, 21(2), pp.261-273.

[16] Newton, T.R., Melkote, S.N., Watkins, T.R., Trejo, R.M. and Reister, L., 2009. Investigation of the effect of process parameters on the formation and characteristics of recast layer in wire-EDM of Inconel 718. Materials Science and Engineering: A, 513, pp.208-215.

[17] Prasad, K.S., Rao, C.S. and Rao, D.N., 2011. Establishing empirical relationships to predict grain size and hardness of pulsed current microplasma arc welded Inconel 625 sheets. Journal of Materials \& Metallurgical Engineering, 1(3), pp.1-10.

[18] Rao, P.S., Ramji, K. and Satyanarayana, B., 2011. Effect of WEDM conditions on surface roughness: A parametric optimization using Taguchi method. International journal of advanced engineering sciences and technologies, 6(1), pp.41-48.

[19] Rao, T.B. and Krishna, A.G., 2013. Simultaneous op- 
timization of multiple performance characteristics in WEDM for machining ZC63/SiC p MMC. Advances in Manufacturing, 1(3), pp.265-275.

[20] Bharathi, R.S., Shanmugam, N.S., Kannan, R.M. and Vendan, S.A., 2018. Studies on the Parametric Effects of Plasma Arc Welding of 2205 Duplex Stainless Steel. High Temperature Materials and Processes, 37(3), pp.219-232.

[21] Sajjadi, S.A., Zolfaghari, G., Adab, H., Allahabadi, A. and Delsouz, M., 2017. Measurement and modeling of particulate matter concentrations: applying spatial analysis and regression techniques to assess air quality. MethodsX, 4, pp.372-390.

[22] Sidhu, S.S., Batish, A. and Kumar, S., 2013. Neural network-based modeling to predict residual stresses during electric discharge machining of $\mathrm{Al} / \mathrm{SiC}$ metal matrix composites. Proceedings of the Institution of Mechanical Engineers, Part B: Journal of Engineering Manufacture, 227(11), pp.1679-1692.

[23] Singh, R. and Singh, B., 2011. Comparison of cryotreatment effect on machining characteristics of titanium in electric discharge machining. International Journal of Automotive and Mechanical Engineering, 3, pp.239-48.

[24] Sone, T. and Masui, K., 1991. Application of ion nitriding to wire-electrical-discharge-machined blanking dies. Materials Science and Engineering: A, 140, pp.486-493.

[25] Srinivasan, R.G., Selvabharathi, R., Palani, S. and Karuppasamy, R., 2019. Influence of high-velocity oxy- gen fuel spraying and plasma nitriding on microstructure properties of iron-nickel-chromium alloy using hybrid surface heat treatment. Materials Research Express, 6(8), p.086584.

[26] Tarng, Y.S., Ma, S.C. and Chung, L.K., 1995. Determination of optimal cutting parameters in wire electrical discharge machining. International Journal of Machine Tools and Manufacture, 35(12), pp.1693-1701.

[27] Warren, A.W., Guo, Y.B. and Weaver, M.L., 2006. The influence of machining induced residual stress and phase transformation on the measurement of subsurface mechanical behavior using nanoindentation. Surface and Coatings Technology, 200(11), pp.3459-3467.

[28] Williams, R.E. and Rajurkar, K.P., 1991. Study of wire electrical discharge machined surface characteristics. Journal of materials processing technology, 28(1-2), pp.127-138.

[29] Xiong, G., Zheng, M., Li, D., Zhao, L., Wang, Y. and Li, M., 2010, October. Study on the influence of nonelectrical parameters on processing quality of WEDMHS and improvement measures. In International Conference on Computer and Computing Technologies in Agriculture (pp. 514-520). Springer, Berlin, Heidelberg.

Received 10-02-2021

Accepted 14-03-2021 